\title{
RECUPERAÇÃO DE COBALTO E DE LÍTIO DE BATERIAS ÍON-LÍTIO USADAS
}

\author{
Natália Giovanini Busnardo, Jéssica Frontino Paulino e Julio Carlos Afonso* \\ Departamento de Química Analítica, Instituto de Química, Universidade Federal do Rio de Janeiro, CP 68563,
}

21949-900 Rio de Janeiro - RJ, Brasil

Recebido em 6/1/06; aceito em 6/9/06; publicado na web em 26/3/07

\begin{abstract}
RECOVERY OF COBALT AND LITHIUM FROM SPENT Li-ION BATTERIES. The "active mass" (cathode + anode + electrolyte) of spent $\mathrm{Li}$-ion batteries was submitted to one of the following procedures: (a) it was calcined $\left(500^{\circ} \mathrm{C}\right)$ and submitted to extraction with water to recover lithium salts. The residual solid was treated with sulfuric acid containing hydrogen peroxide. Cobalt was recovered as sulfate; (b) the "active mass" was treated with potassium hydrogen sulfate $\left(500{ }^{\circ} \mathrm{C}\right)$ and dissolved in water. Cobalt was precipitated together with copper after addition of sodium hydroxide. Lithium was partially recovered as lithium fluoride. Coprocessing of other battery components (aluminum and copper foils) affected negatively the behavior of the recovery procedures. Previous segregation of battery components is essential for an efficient and economical processing of the "active mass".
\end{abstract}

Keywords: spent Li-ion batteries; metal recovery; cobalt.

\section{INTRODUÇÃO}

No segmento das baterias recarregáveis, por razões ambientais e de eficiência, houve a partir de 1990 a inserção no mercado consumidor das baterias de níquel metal-hidreto (Ni-MH) e de íonlítio ${ }^{1}$. No mercado europeu o percentual de participação dessas últimas no segmento da energia portátil passou de 8, em 1999, para $18 \%$, em $2003^{2}$. Em escala mundial as pilhas e baterias à base de lítio detiveram $28 \%$ do mercado nesse mesmo ano $^{3}$. Em 2004, a produção mundial de baterias de íon-lítio chegou à ordem de 700 milhões de unidades ${ }^{4}$ (500 milhões em $2000^{5}$ e 250 milhões em 19986). A expectativa em torno do carro elétrico e a versatilidade de formatos ampliaram as possibilidades de aplicação dessa bateria $^{7}$. Nela, emprega-se ao invés de lítio metálico, íons lítio, $\mathrm{Li}^{+}$, presentes no eletrólito na forma de sais dissolvidos em solventes não aquosos; no catodo freqüentemente na forma do óxido misto $\mathrm{LiCoO}_{2}$ (outros compostos empregados são ${ }^{8,9} \mathrm{LiNiO}_{2}, \mathrm{LiMn}_{2} \mathrm{O}_{4} \mathrm{e}$ $\left.\mathrm{LiCo}_{1-\mathrm{x}} \mathrm{Ni}_{\mathrm{x}} \mathrm{O}_{2}\right)$ e, no anodo, intercalado na estrutura do grafite, formando o composto $\mathrm{LiC}_{\mathrm{y}}(0<\mathrm{y}<6)$. No processo de descarga, os íons lítio migram do anodo para o catodo. A distância entre os dois pólos é muito pequena, normalmente cerca de 50 micrômetros $(0,05$ $\mathrm{mm}$ ). Para evitar o contato, eles são separados por uma folha de material polimérico, como poliamida ou polipropileno.

Algumas das principais características das baterias de íon-lítio são $0^{2,8,10}$ alta densidade de energia, longos ciclos de vida, baixíssima taxa de autodescarga e segurança no manuseio. Além disso, o fato de empregarem materiais de baixa densidade permite que sejam projetadas para terem massa e tamanho reduzidos.

A consequiência da expansão do mercado para essa bateria é o aumento da sua participação no chamado lixo tecnológico nos próximos $\operatorname{anos}^{11}$ (a vida útil média é de $2 \operatorname{anos}^{10}$ ). Isso demonstra a necessidade de se implementar um sistema de coleta do produto usado e de desenvolver processos de reciclagem adequados para esse material ${ }^{1,3,8}$. Estima-se que a geração de resíduos de baterias usadas chegará de 200 a 500 t/ano, com teores (em massa) de cobalto entre 5 e $20 \%$, bem como de 2 a $7 \%$ de lítio ${ }^{5,6}$.

\footnotetext{
*e-mail: julio@iq.ufrj.br
}

O cobalto é o componente mais valioso, juntamente com o eletrólito ${ }^{11}$. Conseqüentemente, o processo de reciclagem necessitará recuperar pelo menos esse elemento químico. Seu preço apresentou de 1998 a 2004 um valor de mercado entre US\$20 e 50 por $\mathrm{kg}$, com tendência crescente nos últimos anos, tornando atrativo o processamento das baterias usadas para recuperação do cobalto presente ${ }^{4,11}$. A recuperação do eletrólito é muito difícil face à fragilidade ${ }^{11}$ frente à água, à umidade do ar e ao aquecimento $\left(\mathrm{T}_{\text {dec }}\right.$ ca. $\left.80^{\circ} \mathrm{C}\right)$. Uma tentativa é a extração por solvente à baixa temperatu$\mathrm{ra}^{11}$. Mesmo assim, fora essa dificuldade de ordem prática, ele é susceptível a reações de decomposição ao longo da vida útil da bateria, especialmente na superfície do anodo.

A princípio, o processamento da bateria de íon-lítio usada é relativamente simples devido essencialmente à química bem diferenciada de seus componentes principais (lítio, cobalto e carbono). Elas são praticamente as únicas que contêm este metal alcalino que são empregadas em estudos de reciclagem, provavelmente por duas razões: o mercado consumidor deste produto é muito superior ao da pilha primária $\mathrm{Li} / \mathrm{MnO}_{2}$, estando ainda em franca expansão e, o produto contém elementos de alto valor agregado (cobalto), em teor bastante considerável. Elas são essencialmente processadas em escala comercial ${ }^{4,11}$ em dois países: Canadá e Estados Unidos. Na Europa, ainda não se tem um processamento efetivo nessa escala.

O aspecto mais crítico é a abertura da bateria, devido ao risco de ignição do solvente (não aquoso) face ao aquecimento pelo atrito na abertura da blindagem de aço e à possibilidade de curto-circuito nessa etapa do processamento ${ }^{5,11,12}$. Além disso, é preciso levar em conta a presença de quantidades variáveis de outros elementos, os quais podem colocar dificuldades no processo de reciclagem. Por isso, acredita-se que não se esgotou o rol de possibilidades para estabelecer novos processos de recuperação de componentes dessas baterias. Por ex., extrações em fase sólida - que dispensam a dissolução da bateria em meio aquoso - e agentes complexantes - que favorecem a solubilização seletiva de metais estão em curso em vários centros de pesquisa ${ }^{1,12}$, o que proporciona a geração de menos resíduos finais de processo.

Os processos já propostos na literatura em escala laboratorial empregam dissolução em ácidos clorídrico ${ }^{10,13}$, nítrico ${ }^{5,6,8}$ ou sulfúrico $^{1,4,14}$ diluídos, seguida de tratamento do líquido ácido e do 
processamento do resíduo final. É freqüente a adição de peróxido de hidrogênio à solução ácida ${ }^{4-6,14} \mathrm{a}$ fim de converter todo o cobalto ao número de oxidação +2 . O cobalto pode se recuperado por via eletroquímica ${ }^{4}$, precipitação $0^{5,6}$ ou extração por solvente ${ }^{13}$. O lítio pode ser recuperado conjuntamente com o cobalto via síntese do óxido $\mathrm{LiCoO}_{2}$ (material constituinte do catodo) ${ }^{6}$ ou como carbonato $\left(\mathrm{Li}_{2} \mathrm{CO}_{3}\right)^{1}$, precipitado a $100{ }^{\circ} \mathrm{C}$, tirando-se proveito da menor solubilidade deste sal àquela temperatura ${ }^{15}$. Contudo, em geral, não é citada a recuperação individual do lítio, talvez pela dificuldade tanto de extraí-lo como de precipitá-lo. A calcinação prévia da massa catodo + anodo + eletrólito dificulta a solubilização e a reatividade da massa calcinada contendo lítio e cobalto (além da destruição do eletrólito). Daí a pouca menção a este pré-tratamento ${ }^{14}$; o carbono costuma ser recuperado como resíduo insolúvel de processo ${ }^{1,10}$.

$\mathrm{O}$ tratamento dos resíduos precisa incluir o gerenciamento do flúor - grave poluente ambiental - presente na formulação do eletrólito, o que vem estimulando a substituição deste por polímeros sólidos condutores ${ }^{12,16,17}$. Isso tem levado ao desenvolvimento das chamadas baterias de lítio-polímero, que armazenam até 50\% mais energia que as baterias de íon-lítio. Além disso, quando comparadas a estas últimas, são mais leves, têm vida útil até duas vezes maior e não contêm solventes - onde se dissolve o eletrólito - dispensando, assim, a blindagem metálica, bastando um invólucro plástico.

Este trabalho buscou desenvolver processos hidrometalúrgicos inovadores aplicáveis às baterias de íon-lítio, com ênfase na recuperação do cobalto, do lítio e demais componentes do produto. Além disso, foi feito um mapeamento de todos os resíduos finais dos processos desenvolvidos, assunto geralmente ignorado na literatura, a fim de adequá-los às normas ambientais vigentes.

\section{PARTE EXPERIMENTAL}

\section{Matérias-primas}

Foram empregadas 20 baterias de íon-lítio de diferentes fornecedores, fabricadas entre 2001 e 2003 , todas de formato prismático, empregadas em telefones celulares. As baterias achavam-se descarregadas (voltagem desprezível) e foram colocadas em congelador à $-5^{\circ} \mathrm{C}$.

A seguir, as baterias foram desmontadas manualmente, em capela. Após a abertura da blindagem de aço, foram colocadas em sistema de vácuo por 20 min para remoção e condensação do solvente presente. Na sequiencia, a bateria sem o solvente foi aberta por completo, permitindo distingüir seus componentes: carcaça externa (plástica, contendo os contatos elétricos); blindagem de aço; separador catodo/anodo, de cor branca, de material polimérico correspondendo a polietileno ou poliamida; lâmina de alumínio (suporte do anodo - $\mathrm{LiC}_{\mathrm{y}}$ ); lâmina de cobre (suporte do catodo $\mathrm{LiCoO}_{2}$ ); o eletrólito dispersa-se no catodo e no anodo. É essencial eliminar por completo o solvente, pois a presença de quantidades residuais dificulta a separação da massa do catodo aderida à lâmina de cobre e da massa de anodo aderida à lâmina de alumínio, com risco de fragmentação das mesmas. As separações acima foram feitas por vibração mecânica e raspagem do pó. As massas de todos os componentes das baterias foram determinadas por meio de balança analítica. A Figura 1 ilustra alguns desses componentes. Para os experimentos, empregou-se a massa correspondente ao catodo + anodo + eletrólito ("massa ativa"). Posteriormente efetuaram-se alguns experimentos onde se acrescentou à massa acima as lâminas de cobre, de alumínio e o separador polimérico. Em todos os casos, procedeu-se a uma moagem prévia para homogeneização do material.

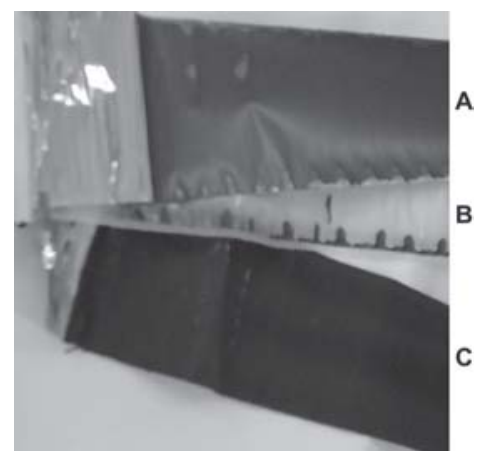

Figura 1. Ao desenrolar as camadas, o separador polimérico (B) se interpõe entre a lâmina de alumínio (A - contendo sólido de cor cinza correspondendo ao anodo - $\mathrm{LiC}_{y}$ ) e a lâmina de cobre $(C)$ sobre a qual se deposita o catodo $\left(\mathrm{LiMnO}_{2}\right)$, de coloração preta

\section{Procedimento - rota de fusão}

Neste procedimento empregou-se uma relação mássica amostra/fundente de 1:9. O fundente utilizado foi o hidrogenossulfato de potássio $\left(\mathrm{KHSO}_{4}\right)$. A fusão foi conduzida em mufla a $500{ }^{\circ} \mathrm{C}$ por $5 \mathrm{~h}$, com acesso contínuo de ar para evitar a redução de parte do sulfato a sulfeto devido ao carbono presente no catodo. A massa fundida resfriada foi dissolvida em água $(250 \mathrm{~mL}$ para cada massa processada) a $90{ }^{\circ} \mathrm{C}(300 \mathrm{rpm})$ em $1 \mathrm{~h}$. A solução obtida, de tonalidade rosa (devido ao íon $\mathrm{Co}^{2+}$ ) foi lentamente vertida em solução de hidróxido de sódio $\left(12,5 \mathrm{~mol} \mathrm{~L}^{-1}\right)$ de modo que, após a mistura, o $\mathrm{pH}$ se mantivesse acima de 10 . O precipitado contendo cobalto foi filtrado e lavado com água até $\mathrm{pH}$ neutro e ausência de íons $\mathrm{Na}^{+}$

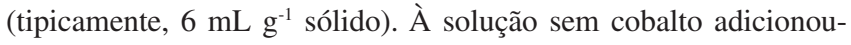
se, vagarosamente, solução saturada de fluoreto de potássio, obtendo-se um precipitado branco-translúcido de fluoreto de lítio (LiF), que foi filtrado e lavado com solução de ácido fluorídrico $0,01 \mathrm{~mol} \mathrm{~L}^{-1}\left(3 \mathrm{~mL} \mathrm{~g}^{-1}\right)$ e depois com água a $5-10{ }^{\circ} \mathrm{C}\left(3 \mathrm{~mL} \mathrm{~g}^{-1}\right) . \mathrm{O}$ efluente final líquido foi tratado com solução saturada de sulfato de cálcio, precipitando os íons fosfato e fluoreto remanescentes em solução e, por fim, neutralizado com solução de ácido sulfúrico 2 mol L-1. A Figura 2 ilustra o fluxograma do processo descrito.

\section{Procedimento - rota de calcinação prévia}

A amostra foi calcinada em mufla a $500{ }^{\circ} \mathrm{C}$ por $5 \mathrm{~h}\left(3{ }^{\circ} \mathrm{C} \mathrm{min}{ }^{-1}\right)$. Esse procedimento levou à eliminação do carbono presente no catodo. O sólido calcinado foi submetido à extração em aparelhagem tipo Soxhlet com água $(24$ h) para remoção de sais de lítio presentes. A solução aquosa obtida, de aspecto turvo, foi evaporada, fornecendo um sólido branco fosco. O sólido não extraído foi tratado com uma mistura $1: 1 \mathrm{vol} / \mathrm{vol}$ de ácido sulfúrico concentrado e água a $90-100{ }^{\circ} \mathrm{C}$ ( $3 \mathrm{~mL}$ da mistura $\mathrm{g}^{-1}$ sólido), com adições periódicas de peróxido de hidrogênio $(36 \% \mathrm{~m} / \mathrm{m})$ para reduzir todo o cobalto ao número de oxidação +2 . Não se utilizou ácido nítrico porque não tem efeito sobre o precipitado e ácido clorídrico porque $\mathrm{Co}(\mathrm{III})$ reage com liberação de gás cloro. Após a dissolução total da massa (cerca de $2 \mathrm{~h}$ ), passou-se à fase de evaporação da solução, de intensa cor rosa-avermelhada; após $2 \mathrm{~h}$ cristalizou um sólido lilás brilhante, correspondendo a $\mathrm{CoSO}_{4} \cdot 7 \mathrm{H}_{2} \mathrm{O}$, que foi filtrado a vácuo em cadinho filtrante de vidro sinterizado, lavado com etanol e seco à temperatura ambiente. A solução ácida residual foi neutralizada com hidróxido de sódio $\left(12,5 \mathrm{~mol} \mathrm{~L}^{-1}\right)$ para precipitação dos metais presentes, mas também tentou-se seu reaproveitamento no processamento de novos sólidos contendo cobalto. A Figura 3 ilustra o esquema de processamento desta rota. 


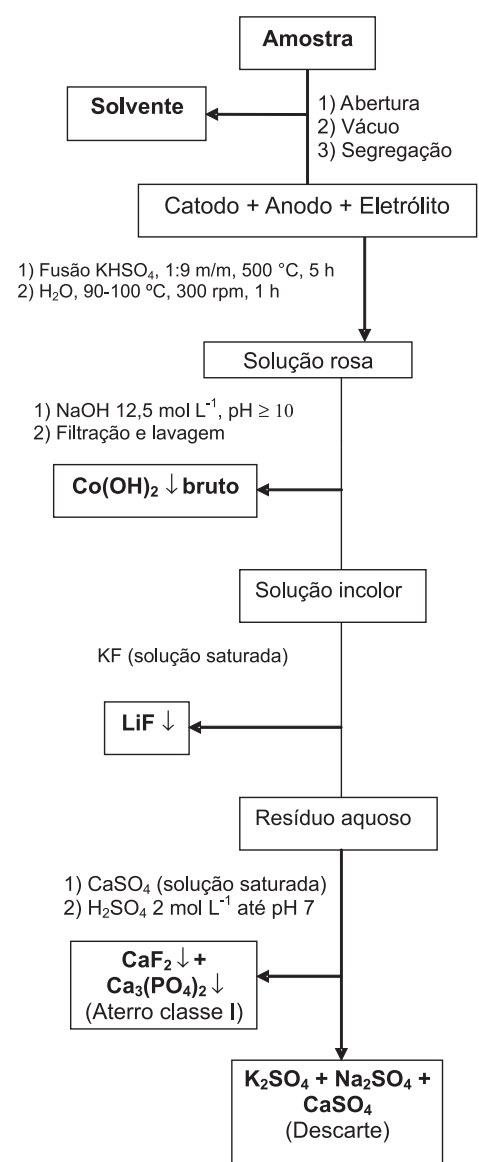

Figura 2. Processamento da bateria de íon-lítio baseado na fusão da "massa ativa" (catodo + anodo + eletrólito) com hidrogenossulfato de potássio $\left(500{ }^{\circ} \mathrm{C}, 5 \mathrm{~h}\right.$, razão mássica amostra/fundente 1:9)

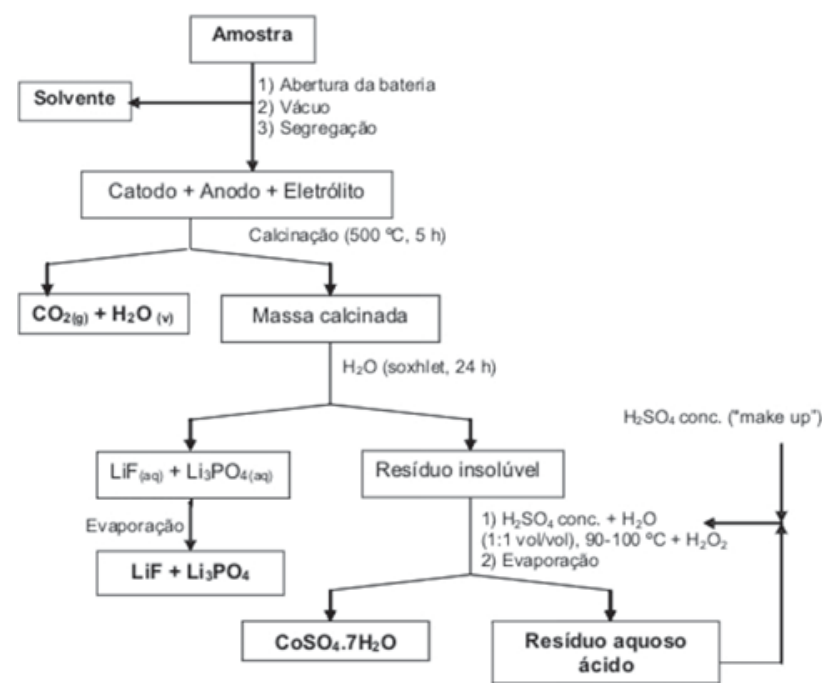

Figura 3. Processamento da bateria de íon-lítio baseado na calcinação inicial da "massa ativa" $\left(500{ }^{\circ} \mathrm{C}, 5 \mathrm{~h}\right)$, seguido de extração de sais de lítio com água e dissolução do sólido contendo cobalto em ácido sulfúrico

\section{Métodos analíticos}

Os metais (em solução) foram analisados por absorção atômica (Perkin Elmer AAS 3300), cujos limites de detecção, determinados experimentalmente, são cobalto, alumínio e cobre: $0,5 \mathrm{mg} \mathrm{L}^{-1}$; lítio: $1 \mathrm{mg} \mathrm{L}^{-1}$. As amostras foram dissolvidas em água régia para essa análise. Os íons fosfato e fluoreto foram dosados através da cromatografia de íons (Dionex DX 100, limite de detecção 0,01 mg $\mathrm{L}^{-1}$ ). A difração de raios-x (DRX) foi empregada para avaliação das fases cristalinas existentes em diversos sólidos obtidos ao longo do processamento da bateria (difratômetro Philips PW 1820; fonte de radiação $\mathrm{Cu}-\mathrm{K} \alpha$, varredura angular (2 teta) $12-70^{\circ}$, com passo de $0,020^{\circ}$ e tempo de $1 \mathrm{~s}$ por passo; as amostras apresentavam granulometria menor que $0,0044 \mathrm{~mm}$ ). A fluorescência de raios-x (FRX) foi usada na análise química desses mesmos sólidos (aparelho de fluorescência Rigaku K-1800, usando como fonte de radiação $\mathrm{Cu}$ $\mathrm{K} \alpha$. Curvas de calibração foram estabelecidas para cobalto, cobre, alumínio e lítio, sendo que as concentrações das soluções-padrão variaram de 0,1 a $10 \mathrm{~g} \mathrm{~L}^{-1}$ ). As análises quantitativas foram complementadas por ensaios qualitativos clássicos para as soluções e os sólidos ${ }^{15}$. O solvente orgânico foi analisado por infravermelho.

\section{RESULTADOS E DISCUSSÃO}

\section{Composição das baterias}

A composição das baterias de íons-lítio mostrou-se mais complexa que a da pilha $\mathrm{Li} / \mathrm{MnO}_{2}{ }^{18}$. A carcaça plástica externa, que dá o formato da bateria, representa $23 \% \mathrm{~m} / \mathrm{m}$ da mesma. A blindagem de aço $(10,5 \% \mathrm{~m} / \mathrm{m})$ do produto em si é bem menos espessa que aquela das pilhas e baterias comuns pelo fato do meio interno não ser corrosivo; contudo, isso aumenta o risco de liberação de componentes internos (incluindo o solvente) para o meio ambiente em caso de corrosão da blindagem do produto descartado de forma inadequada (lixões, terrenos baldios etc.).

A fração que corresponde à "massa ativa" (anodo, catodo e eletrólito) perfaz quase $40 \%$ da massa da bateria. A FRX permitiu evidenciar nesse sólido a presença de cobalto, lítio e cobre como metais principais. Outros metais encontrados em quantidades-traço foram alumínio, cálcio e níquel; apenas picos referentes ao fósforo foram encontrados, evidenciando a presença do eletrólito hexafluorofosfato de lítio ( $\left.\mathrm{LiPF}_{6}\right)$ em todas as amostras, o que confirma seu uso dominante na literatura ${ }^{19}$. Não foi possível quantificar o eletrólito isoladamente porque se acha disperso pelo catodo, anodo e separador. Os dois componentes mais valiosos (cobalto e eletrólito) estão presentes nessa fração da bateria. Os procedimentos de calcinação prévia indicam que o carbono corresponde a cerca de $32 \% \mathrm{~m} / \mathrm{m}$ da "massa ativa" (ou $13 \% \mathrm{~m} / \mathrm{m}$ de toda a bateria, o que concorda com o valor relatado na literatura, cerca de $16 \% \mathrm{~m} / \mathrm{m}^{5,14}$ ).

Os solventes nãos aquosos encontrados foram o carbonato de propileno (75\% das amostras), 1,3-dioxolana (20\% das amostras) e dimetoxietano (5\% das amostras), representando em média 4,5\% $\mathrm{m} / \mathrm{m}$ da composição da pilha. A lâmina de cobre corresponde a $8,9 \% \mathrm{~m} / \mathrm{m}$, enquanto que a de alumínio compõe $6,1 \% \mathrm{~m} / \mathrm{m}$ do produto. O separador polimérico responde por $5,3 \% \mathrm{~m} / \mathrm{m}$ da bateria e os contatos elétricos, pelos $2,7 \%$ restantes. Os valores encontrados para alumínio, cobre, separador polimérico e solvente estão bem dentro da faixa de teores relatada na literatura ${ }^{19,20}$.

\section{Recuperação do lítio}

Os primeiros ensaios de separação enfocaram a extração direta de sais de lítio na massa original com água em refluxo por $24 \mathrm{~h}$. A presença de carbono (grafite), meio fortemente adsorvente, dificultou a recuperação desses sais. Por isso, a alternativa tentada foi a pré-calcinação em mufla a fim de eliminar o carbono. Esse procedimento melhorou enormemente o rendimento do processo. Enquanto que a recuperação de lítio chega a cerca de $90 \% \mathrm{~m} / \mathrm{m}$ com a amostra calcinada, esse valor não atinge sequer $10 \%$ quando do 
tratamento da amostra contendo carbono. A recuperação considerável do lítio contrasta com a dificuldade em termos de reatividade e solubilização da massa calcinada relatada na literatura ${ }^{14}$. Isso talvez se explique pela baixa taxa de aquecimento empregada, a qual evita a ignição do carbono e a conseqüente geração de picos de temperatura, o que favorece a formação de óxidos mistos e outros compostos mais difíceis de solubilizar.

Ensaios qualitativos ${ }^{15}$ acusaram que o lítio se acha contido em dois sais, fluoreto e fosfato. Esses compostos são pouco solúveis em água ( $\mathrm{LiF}, 2,7 \mathrm{~g} \mathrm{~L}^{-1} ; \mathrm{Li}_{3} \mathrm{PO}_{4}, 0,3 \mathrm{~g} \mathrm{~L}^{-1}$ a $25^{\circ} \mathrm{C}$ ), o que ajuda a explicar a baixa recuperação dos mesmos em presença de um meio adsorvente como grafite. Os compostos acima identificados estão de acordo com as reações envolvendo a degradação do eletrólito sob hidrólise em presença da umidade do $a^{11}$. Os dados de cromatografia de íons indicam que, em média, o fluoreto de lítio compõe $70 \% \mathrm{~m} / \mathrm{m}$ do sólido total. A recuperação do lítio na forma dos dois sais acima mencionados supera o rendimento obtido na recuperação como carbonato $\mathrm{Li}_{2} \mathrm{CO}_{3}$ (em torno de $\left.70 \% \mathrm{~m} / \mathrm{m}\right)^{1}$. Ambos os sais de lítio são de alto valor agregado ${ }^{21}$, mas é necessário o tratamento da mistura deles para obtenção de apenas um dos compostos.

$\mathrm{Na}$ rota de processamento via fusão com hidrogenossulfato de potássio, o lítio é recuperado após o isolamento do cobalto (Figura 2). O rendimento é inferior ao da rota de calcinação, principalmente devido ao aumento de volume após a adição da solução contendo cobalto à solução de hidróxido de sódio e a lavagem do precipitado de hidróxido de cobalto. Apesar disso, o lítio é obtido na forma de um único composto $(\mathrm{LiF})$, cuja análise por cromatografia de íons dá uma pureza acima de $99 \% \mathrm{~m} / \mathrm{m}$, e o difratograma da Figura 4 mostra que se trata de um sólido bem cristalizado. Deve-se salientar também que não se pode precipitar o lítio como fluoreto antes do isolamento do cobalto porque o sal $\mathrm{CoF}_{2}$ não é muito solúvel em água ${ }^{15}$; como a quantidade de cobalto é bem superior à do lítio, o seu fluoreto acabará por co-precipitar com o sal deste último.

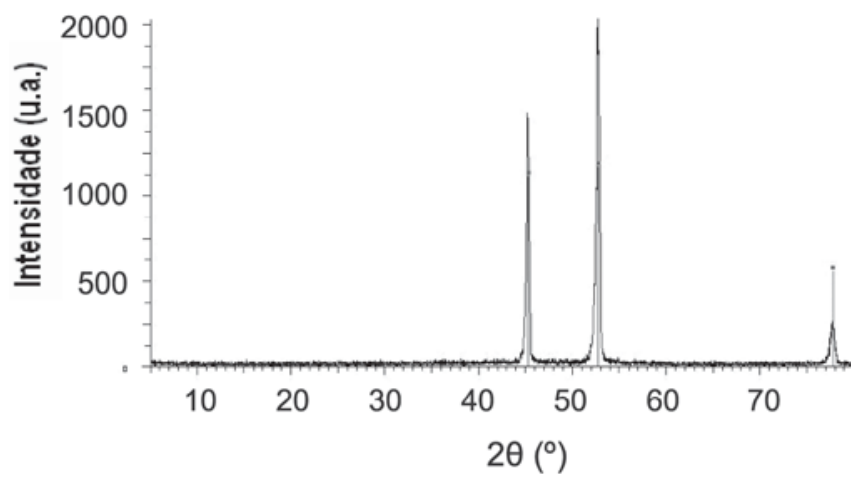

Figura 4. Difratograma de raios-x do fluoreto de lítio (ver fluxograma da Figura 2)

\section{Recuperação do cobalto}

Na rota de calcinação prévia, após a extração dos sais de lítio, o sólido apresentava-se na forma de um pó cinza escuro. A DRX (Figura 5) acusou a presença de picos bem definidos do óxido misto $\mathrm{LiCoO}_{2}$. Isto explica a não recuperação quantitativa do metal alcalino por extração com água, visto que este composto é insolúvel. Há ainda pequenos picos correspondentes ao óxido de fórmula $\mathrm{Co}_{3} \mathrm{O}_{4}$. A opção de tratar este sólido com ácido sulfúrico visava a obtenção de um produto final de cobalto de pureza elevada. A dissolução do sólido foi um processo lento, reflexo da necessidade de reduzir todo o cobalto ao estado divalente para assegurar sua solubilização total (é bem conhecido o efeito positivo da água oxi- genada na recuperação do cobalto $\left.{ }^{6,14,20}\right)$. O tratamento direto da "massa ativa" original com ácido sulfúrico nas mesmas condições experimentais deu-se em menos tempo (60-80 min), mas houve dificuldade de isolar o carbono e de lavá-lo até a remoção de cobalto e da acidez $\left(15 \mathrm{~mL} \mathrm{~g}^{-1}\right)$, o que aumentou o consumo de água e diluiu a solução ácida final, elevando o consumo energético e o tempo da etapa de evaporação (Figura 3). O carbono isolado desta forma corresponde a cerca de $30 \%$ da "massa ativa" $(12 \% \mathrm{~m} / \mathrm{m}$ de toda a bateria). Consideradas as perdas de manipulação de um material untuoso como o grafite, esse resultado concorda com o obtido após a calcinação prévia (32 e $13 \%$ m/m, respectivamente).

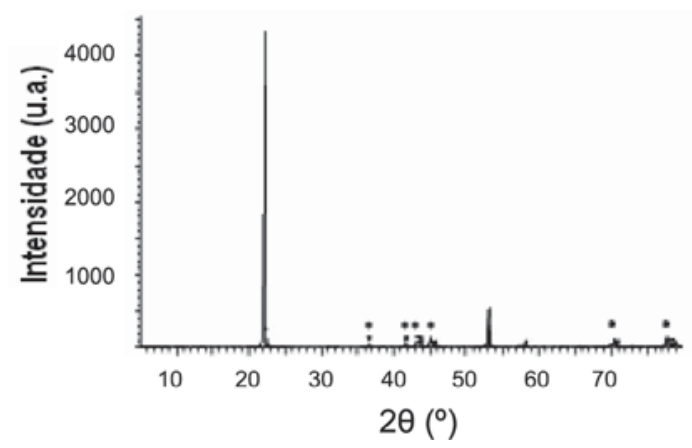

Figura 5. Difratograma de raios- $x$ do óxido $\mathrm{LiCoO}_{2}$, obtido após calcinação prévia e extração de sais de lítio com água (ver fluxograma da Figura 3). Os picos assinalados com asterisco correspondem ao composto $\mathrm{Co}_{3} \mathrm{O}_{4}$

O sal $\mathrm{CoSO}_{4} .7 \mathrm{H}_{2} \mathrm{O}$ obtido apresenta excelente grau de pureza, acima de $99,5 \% \mathrm{~m} / \mathrm{m}$, conforme dados de absorção atômica. O cobre, o alumínio e o lítio não foram detectados dentro das condições de análise.

A solução ácida final, de coloração acastanhada, contém cobalto, cobre e lítio. Dados de absorção atômica indicam que cerca de $6 \%$ $\mathrm{m} / \mathrm{m}$ do cobalto total da bateria se acha nesta solução, bem como praticamente todo o cobre e $10 \%$ do lítio. A neutralização com hidróxido de sódio, além de consumir enorme quantidade do neutralizante, gerou um efluente final salino de alta concentração, a ponto de ter sido necessária a adição de água para solubilizar o sulfato de sódio que precipita no momento da neutralização. Após superar essa dificuldade, obtém-se um sólido marrom escuro, correspondendo aos hidróxidos de cobalto e cobre co-precipitados. A solução neutralizada é incolor. Os sais de cálcio precipitados (fosfato/fluoreto) dessa solução (Figura 1), que podem ser destinados a aterros industriais classe I, correspondem a menos de $2 \%$ da massa da bateria inicial processada.

A alternativa foi reaproveitar a solução ácida após a cristalização do sulfato de cobalto, para tratamento da massa calcinada de outra bateria. O cuidado aqui foi adicionar ácido sulfúrico para compensar as perdas na cristalização do sulfato de cobalto ("make up"). Pelo menos para dois processamentos consecutivos o resultado foi bastante animador - o sulfato cristalizado tinha pureza similar em todos os casos e o rendimento em massa de recuperação do cobalto situou-se na ordem de $94 \%$. A tendência com o uso repetido da solução ácida é o aumento da concentração de cobre até o ponto de seu sulfato co-cristalizar com o sal de cobalto, contaminando o produto final de interesse. Uma alternativa viável para contornar esse problema é a remoção do cobre dessa solução sulfúrica por extração com solventes ${ }^{22,23}$.

No caso do processamento pela rota de fusão, a recuperação do cobalto atingiu valores acima de $99 \% \mathrm{~m} / \mathrm{m}$, face à seletividade da reação de precipitação empregada. Contudo, o cobre e traços de fosfato se acham igualmente presentes nesse precipitado. O cobre 
compõe cerca de $3 \% \mathrm{~m} / \mathrm{m}$ do precipitado, o que exige uma etapa de purificação suplementar. O precipitado bruto de hidróxido de cobalto foi dissolvido em ácido clorídrico, de modo que o $\mathrm{pH}$ ficasse em torno de 2. Adicionou-se, gota a gota, solução $3 \mathrm{~mol} \mathrm{~L}^{-1}$ de tioacetamida $\left(90^{\circ} \mathrm{C}, 200 \mathrm{rpm}\right)$, precipitando o cobre como sulfeto $(\mathrm{CuS})$. O cobalto foi reprecipitado por adição de hidróxido de sódio (12,5 $\left.\mathrm{mol} \mathrm{L}^{-1}\right)$ até $\mathrm{pH} \mathrm{8-9,} \mathrm{sendo} \mathrm{posteriormente} \mathrm{filtrado,} \mathrm{lavado}$ com água $\left(3 \mathrm{~mL} \mathrm{~g}^{-1}\right)$ e seco em estufa a $150{ }^{\circ} \mathrm{C}$ por $2 \mathrm{~h}$. A precipitação do sulfeto de cobre em meio ácido é uma alternativa simples de separar cobalto de cobre com alto rendimento ${ }^{24}$ (a recuperação de ambos os metais supera $99,5 \% \mathrm{~m} / \mathrm{m}$ ) e pureza elevada em cada produto final (acima de $99,5 \% \mathrm{~m} / \mathrm{m}$ ).

\section{Efeito da adição das lâminas de cobre e alumínio e do separador polimérico}

Com a queima do material orgânico na etapa de calcinação ou durante a fusão, a inclusão dos componentes acima implicou na introdução de alumínio e do cobre na amostra a ser trabalhada, segundo os esquemas concebidos para processamento da "massa ativa".

Na rota de calcinação prévia, verificou-se uma drástica redução do lítio recuperado na extração com água: a remoção do metal alcalino chegou a $35 \% \mathrm{~m} / \mathrm{m}$, menos da metade da recuperação verificada anteriormente (cerca de $90 \% \mathrm{~m} / \mathrm{m}$ ). Presume-se que a formação de óxidos mistos e oclusão física dos sais de lítio expliquem esse fato. $\mathrm{Na}$ evaporação da solução para cristalização do sulfato de cobalto, a recuperação deste com pureza de $99,5 \%$ atingiu $60 \% \mathrm{~m} / \mathrm{m}$, isto é, uma redução de $1 / 3$ do rendimento anterior $(94 \% \mathrm{~m} / \mathrm{m})$. Quando a recuperação do cobalto atingiu $94 \% \mathrm{~m} / \mathrm{m}$, seu sulfato compunha apenas $78 \%$ da massa cristalizada. Como as concentrações de alumínio e de cobre são agora muito maiores, a co-cristalização de seus sulfatos passa a ocorrer antes do que sucedia na ausência dos novos componentes da bateria adicionados ao processo.

Na rota de fusão, o isolamento dos hidróxidos de cobalto e cobre e subseqüiente processamento por dissolução em meio ácido e tratamento com tioacetamida não apresentou problemas, obtendo-se a mesma recuperação dos dois metais, com pureza similar de seus produtos finais. Já a recuperação do lítio sofreu interferência devido à presença do alumínio. Quando da adição de fluoreto de potássio, houve a precipitação dos sais $\mathrm{Na}_{3} \mathrm{AlF}_{6}$ e $\mathrm{K}_{3} \mathrm{AlF}_{6}$, mais insolúveis em água que os sais $\mathrm{Li}_{3} \mathrm{AlF}_{6}$ e $\mathrm{LiF}^{15,25}$. A melhor alternativa encontrada foi precipitar o alumínio juntamente com o cobalto e o cobre pelo ajuste do pH (por adição de hidróxido de sódio) a 8, e não acima de 10 como antes. O lítio foi isolado como fluoreto (Figura 2), essencialmente com o mesmo rendimento dos experimentos sem alumínio. O precipitados dos hidróxidos dos três elementos foi dissolvido em ácido clorídrico e o cobre foi precipitado como sulfeto. A seguir, a solução foi tratada com hidróxido de sódio até pH acima de 10, precipitando o cobalto. Por fim, a neutralização com ácido sulfúrico permitiu precipitar o alumínio. Caso se neutralizasse a solução após o isolamento do cobalto e do cobre, a recuperação do lítio (como $\mathrm{LiF}$ ) seria mais baixa (da ordem de $35 \% \mathrm{~m} / \mathrm{m}$ ) por conta do maior volume de solução em função da neutralização da mesma antes da adição do reagente precipitante do lítio, ao contrário do procedimento original (Figura 2).

Da discussão acima conclui-se que a introdução de novos componentes nos processos descritos tornou mais delicada a fase de fracionamento, com perda de rendimento na recuperação dos elementos de interesse ou aumento de etapas e consumo maior de regentes e insumos, o que compromete a atratividade das rotas de reciclagem testadas. Isso ilustra o grande desafio de processar materiais multicomponentes, como as baterias usadas. Cada componente tem uma destinação final própria segundo sua natureza. A tendência a nível comercial é a moagem da bateria inteira, com posterior separação de alguns componentes por meios físicos (magnético, peneiramento etc), o que obviamente reduz os custos do processo. Contudo, a segregação dos materiais de um produto multicomponente usado favoreceria enormemente a reciclagem. No presente caso, a carcaça plástica externa, o separador polimérico, o solvente, a blindagem de aço, os contatos metálicos (de cobre) e as lâminas de cobre e de alumínio são diretamente recicláveis. Todos esses componentes respondem por cerca de $60 \% \mathrm{~m} / \mathrm{m}$ da bateria usada. O isolamento das lâminas metálicas no momento da desmontagem da bateria tem também a vantagem de reduzir o consumo de ácido na etapa de abertura após a calcinação prévia ou de fundente e, ainda, a demanda por reagentes e insumos na fase de separação dos elementos. Uma alternativa à raspagem manual (improvável em larga escala) e ao emprego de meios mecânicos é lavar as lâminas com água, seguida de recuperação do sólido via filtração ${ }^{20}$.

\section{Comparação entre as duas rotas de processamento}

A Tabela 1 mostra diversos aspectos relativos às duas metodologias empregadas neste trabalho. A recuperação do solvente é etapa prévia comum aos dois procedimentos, não sendo objeto da presente discussão.

Um problema de ambos os métodos é o íon fosfato, que interfere na pureza do produto final contendo lítio na rota de précalcinação e no produto final de cobalto pela rota de fusão. A tolerabilidade desse analito no produto final determinará a necessidade ou não de processamento adicional de purificação.

Quanto à geração de resíduos, a importância do reciclo é bem clara na rota de calcinação prévia, porque reduz enormemente a

Tabela 1. Desempenho comparativo das duas rotas de processamento da "massa ativa" de baterias de íon-lítio

\begin{tabular}{lcc}
\hline Parâmetro & Processo 1 - rota de fusão & Processo 2 - rota de calcinação prévia \\
\hline Solvente & Recuperação quantitativa & Idem \\
Recuperação do $\mathrm{Li}$ & $50 \% \mathrm{~m} / \mathrm{m}(\mathrm{LiF}>99 \% \mathrm{~m} / \mathrm{m})$ & $90 \% \mathrm{~m} / \mathrm{m}$. Mistura de dois compostos $\left(\mathrm{LiF}+\mathrm{Li}_{3} \mathrm{PO}{ }_{4}\right)$ \\
Recuperação do Co & $>99 \% \mathrm{~m} / \mathrm{m}$. Presença de fosfato & $94 \% \mathrm{~m} / \mathrm{m}$. Alto grau de pureza, \\
& Necessária etapa adicional de & separe e fosfato
\end{tabular}

\begin{tabular}{lcc}
\hline Geração de resíduos & Maior & Menor (reciclo do líquido ácido) \\
\hline Consumo energético & Menor (três fontes: fusão, & dissolução em água e \\
& precipitação do cobre como CuS) & Maior (quatro fontes: calcinação, extração em \\
& KF e NaOH (temperatura ambiente) & Soxhlet, dissolução do sólido contendo cobalto \\
Insumos tóxicos/ & e evaporação da solução sulfúrica) \\
perigosos empregados & $\mathrm{H}_{2} \mathrm{SO}_{4}$ concentrado a quente
\end{tabular}


geração de resíduos finais salinos, bem como economiza insumos e reagentes. Essa filosofia não é possível no caso da rota de fusão. $\mathrm{O}$ uso de excesso de fundente, a reação de isolamento e a metodologia de purificação aplicadas ao cobalto acabam por gerar maior quantidade de resíduos finais. Todavia, este procedimento em termos de segurança é menos perigoso, posto que não são empregadas soluções corrosivas do porte de ácido sulfúrico concentrado sob aquecimento.

A situação inverte-se no caso de se considerar o balanço energético, onde a rota de fusão é menos consumidora de energia. A rota de calcinação tem como aspectos que pesam negativamente: a extração dos sais de lítio, a dissolução do cobalto em ácido sulfúrico e a evaporação prolongada da solução sulfúrica, todas etapas de longa duração.

\section{CONCLUSÕES}

A eficiência de recuperação do cobalto e do lítio de baterias de íon-lítio depende das porções da bateria empregadas nos processos. $\mathrm{O}$ uso apenas da "massa ativa" (anodo + catodo + eletrólito) permitiu obter recuperações excelentes dos dois metais de interesse. A inclusão das lâminas de cobre e de alumínio teve sérios efeitos negativos, reduzindo o percentual de recuperação dos elementos e aumentando o consumo de reagentes e insumos. O ideal seria que o processamento químico da bateria de íon-lítio (e também dos demais tipos de baterias e pilhas usadas) se restringisse à "massa ativa", que é em si constituída por uma mistura de elementos, e onde se encontra a parte mais valiosa (e perigosa) desses produtos. Isso significa a necessidade de conceber modelos que, após o final da vida útil, fossem mais facilmente desmontados, permitindo a segregação da fração que deve realmente ser trabalhada. Por ex., mais de 50\% da massa de uma bateria de íon-lítio segregada é diretamente reciclável.

Dentre os resultados deste trabalho o processo de calcinação prévia teve como mérito a possibilidade de reuso da solução ácida após a cristalização do sulfato de cobalto, reduzindo significativamente a geração de resíduos finais de processo. Estudos acham-se em curso a fim de minimizar o consumo energético e tratar a mistura de fluoreto e fosfato de lítio.

\section{AGRADECIMENTOS}

N. G. Busnardo e J. F. Paulino agradecem ao PIBIC/CNPq/ UFRJ a concessão de bolsa de IC. Agradecemos a G. N. Salvato pelas pesquisas iniciais conduzidas. Ao Centro de Tecnologia Mineral (CETEM) pelas análises de difração de raios-X. Ao Instituto de Engenharia Nuclear (IEN) pelas análises de fluorescência de raios-x. Ao CNPq e à Fundação Universitária José Bonifácio (FUJB) pelo auxílio financeiro.

\section{REFERÊNCIAS}

1. Contestabile, M.; Panero, S.; Scrosati, B.; J. Power Sources 1999, 83, 75.

2. http://www.epba.org/index.html, acessada em Dezembro 2005.

3. Lupi, C.; Pasquali, M.; Miner. Eng. 2003, 16, 537.

4. Lupi, C.; Pasquali, M.; Dell`Era, A.; Waste Management 2005, 25, 215.

5. Lee, C. K.; Rhee, K. I.; Hydrometallurgy 2003, 68, 5.

6. Lee, C. K.; Rhee, K. I.; J. Power Sources 2002, 109, 17.

7. Zhang, P.; Yokoyama, T.; Itabashi, O.; Wakui, Y.; Suzuki, T. M.; Inoue, K.; Hydrometallurgy 1998, 50, 61.

8. Castillo, S.; Ansart, F.; Robert, C. L.; Portal, J.; J. Power Sources 2002, $112,247$.

9. Varela, H.; Huguenin, F.; Malta, M.; Torresi, R. M.; Quim. Nova 2002, 25, 287. 10. Contestabile, M.; Panero, S.; Scrosati, B.; J. Power Sources 2001, 92, 65.

11. Lain, M. J.; J. Power Sources 2001, 97-98, 736.

12. Wakihara, M.; Mater. Sci. Eng., A 2001, R33, 109.

13. Zhang, P.; Yokoyama, T.; Itabashi, O.; Wakui, Y.; Suzuki, T. M.; Inoue, K.; Hydrometallurgy 1998, 47, 259.

14. Shin, S. M.; Kim, N. H.; Sohn, J. S.; Yang, D. H.; Kim, Y. H.; Hydrometallurgy 2005, 79, 172.

15. Lurie, L.; Handbook of Analytical Chemistry, Mir: Moscou, 1978, cap. 6 e 10.

16. Broursely, M.; Archdale, G.; J. Power Sources 2004, 136, 386.

17. Aurbach, D.; J. Power Sources 2005, 146, 71.

18. Paulino, J. F.; Busnardo, N. G.; Afonso, J. C.; Quim. Nova, no prelo.

19. Nazri, G. A.; Pistoia, O.; Lithium Batteries: Science and Technology, Kluwer Academic Publishers: Norwell, 2004.

20. Mantuano, D. P.; Dorella, G.; Elias, R. C. A.; Mansur, M. B.; J. Power Sources 2006, 159, 1510

21. Rydh, C. J.; Svärd, B.; Sci. Total Environ. 2003, 302, 167.

22. Sengupta, B.; Sengupta, R.; Subrahmanyam, N.; Hydrometallurgy 2006, $81,67$.

23. Owusu, G.; Hydrometallurgy 1999, 51, 1.

24. John, L.W.; Prefeasibility Process Flowsheets for Cobalt Recovery, Biometallurgical Pty. Ltd.: Fairfield Gardens, 1998.

25. http://www.solvay-fluor.com/product/lib/0,0,-_EN-1000236,00.html, acessada em Maio 2006. 